\title{
Can onlay's be an alternative restoration for severely damaged primary teeth
}

\author{
Begum Gok Coban ${ }^{1}$, Zuhal Kirzioglu $^{1}$, Ayse Ceren Altun ${ }^{2}$
}

Correspondence: Dr. Begum Gok Coban

Email: kazurat40@hotmail.com
'Department of Pedodontics, Faculty of Dentistry, Süleyman Demirel University, Isparta, Turkiye, 'Department of Oral and Dental Health/Dentistry, Medical Park Hospital, Antalya, Turkiye

\section{ABSTRACT}

Objective: The aim of this study was to evaluate indirect compomer and composite resin onlay restorations of severely damaged primary molars in vivo. Materials and Methods: At the study, 48 restorations, in seven girls and ten boys totally 17 patients aged 4-8, was evaluated clinically with using USPHS criteria for 15 months. Results: The study results revealed that the clinical success rate of compomer and composite onlay restorations was $79 \%$ and $96 \%$, respectively. No significant differences were found statistically between the materials. Conclusions: In the children severely damaged primary molars, onlays are usually worked with an indirect technique in clinics. One of the advantages of indirect technique is being most similar to its original form morphologically.

Key words: Compomer resins, composite resin, dental material, dental restoration, primary teeth

\section{INTRODUCTION}

The demand for tooth color restoration in front teeth as well as in the back teeth has increased in the recent years in pediatric patients. A great number of new materials such as composite resins, ceramic, zircon, or metal-ceramic crowns were introduced for use in cosmetic restorative treatment where substantial crown destruction exists.

It is known that composite resins are widely preferred as they allow for more conservative and direct placement compared to other materials, and as they enable the restoration to be completed in a single session. ${ }^{[1]}$ However, composite resin restorations have certain disadvantages as well as including the difficulty to form bonds while working in the oral cavity, sensitivity to moisture, microleakage, or marginal gap formation due to polymerization shrinkage. ${ }^{[2-4]}$

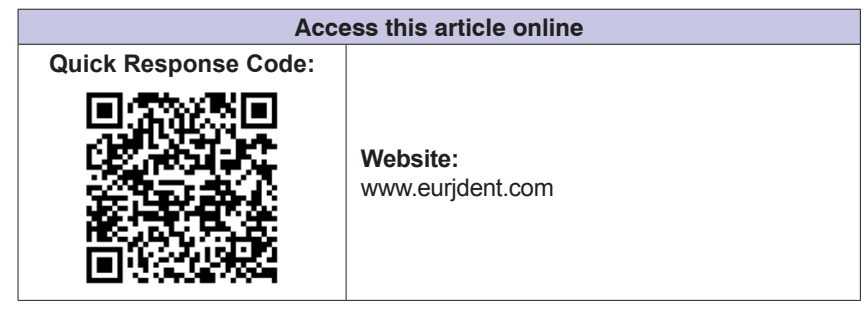

The restoration of large cavities can be accomplished by extraoral polymerization of the resin composite or using the layering technique to avoid polymerization shrinkage and associated problems. The polymerization process itself is another factor which affects the success of treatment. Secondary polymerization by heat curing strengthens the physical properties of the material, the process that prevents the formation of monomers and associated problems that could arise. ${ }^{[5]}$

Enabling secondary polymerization by heat curing not only reinforces the physical properties of the material but also prevents residual monomer formation and problems which may arise correspondingly.

Inlay/onlay systems using composite resin or ceramic blocks combine the advantages of the secondary polymerization method that employ light or heat curing.

This is an open access article distributed under the terms of the Creative Commons Attribution-NonCommercial-ShareAlike 3.0 License, which allows others to remix, tweak, and build upon the work non-commercially, as long as the author is credited and the new creations are licensed under the identical terms.

For reprints contact: reprints@medknow.com

How to cite this article: Coban BG, Kirzioglu Z, Altun AC. Can onlay's be an alternative restoration for severely damaged primary teeth. Eur $\mathrm{J}$ Dent 2017;11:48-52.

DOI: $10.4103 / 1305-7456.202616$ 
Our study evaluated the clinical performance of the indirect composite versus compomer resin placement in the restoration of primary teeth with extensive loss of tooth structure.

\section{MATERIALS AND METHODS}

Seventeen patients ( 7 girls and 10 boys) were selected among the children between 4 and 8 years of age admitted to our clinic, who did not have any medical problems or bad habits, and who scored 3 or 4 according to the Frankl Behavior Scale. ${ }^{[6]}$ A total of 48 first and second primary molar teeth (33 located in the lower jaw and 15 in the upper jaw) were included in the study. The project was approved by the Ethics Committee (Protocol No. 03/10, 16.04.2008). Written informed consent of parents was obtained.

Clinical and radiographic evaluations were conducted on teeth for which an onlay restoration was planned using the indirect method.

Radiographic images and intraoral photos of the relevant tooth/teeth were obtained from the patients selected for radiologic evaluation, and oral hygiene level (Oral Hygiene Index-Simplified [OHI-S]) and the depth of gingival sulcus were measured and recorded before onlay restoration and after treatment at control visits.

Cavity edges were beveled after the removal of the decayed dentin. After the preparation of the cavity onlay, a cavity impression was created by taking the measurement using condensation-type silicone material. The cavity was temporarily restored with noneugenol containing cement (Adhesor Carbofine, Spofa Dental, Jicin, Czech Republic).

An isolator was applied to the cavity walls of the model. Depending on the study group, Z250 (3M/ESPE, St. Paul, MN, USA) or Dyract eXtra (Dentsply DeTrey konstanz, Germany) composite material was placed using the layered technique with a layer thickness of $2 \mathrm{~mm}$, and each layer was light-cured for $20 \mathrm{~s}$ (Blue Swan, Dentanet, Ankara, Turkey). Restorations were placed in Lumamat 100 (Ivoclar Vivadent, Germany) furnace along with plaster models to heat- and light-cure composite resin restoration and to light-cure compomer restorations. Multilink self-etch resin cement (Ivoclar Vivadent, Germany) was used to attach restorations in accordance with the recommendations of the manufacturer. The excess cement was removed. To evaluate the clinical performance of restorations according to the USPHS criteria, patients were scheduled for control visits at 3-month intervals after the treatment at baseline (post polish) and at 1-, 3-, 6-, 9-, 12--, and 15-month recall visits.

The Statistical Package for the Social Sciences software version 18.0; SPSS Inc Inc., Chicago, Illinoise software package was used in the statistical analysis of the data. $P<0.05$ was considered statistically significant. Mann-Whitney U-test was employed to compare the materials at each time point since the data regarding $\mathrm{OHI}-\mathrm{S}$ and the depth of gingival sulcus did not meet the preconditions of parametric tests. Kaplan-Meier survival analysis was used to evaluate the estimated survival of materials and to determine the difference between materials in terms of durability.

\section{RESULTS}

A total of 17 children (7 girls and 10 boys) were included in the study with a mean age of $6.86 \pm 0.71$ years (range: 4-8 years). The distribution of restoration according to teeth and jaw is presented in Table 1.

The longevity of dental restoration implies complete or partial retention in the mouth. Failed restorations by gender, tooth type and age, and the longevity in the mouth are shown in Table 2.

The restorative materials did not differ in terms of anatomic structure, color match, marginal discoloration, secondary caries, and surface structure $(P>0.005)$. The clinical parameters related with restorations are presented in Table 3.

The data on oral hygiene were compared using the Friedman test. The differences between the average ranks are shown in Table 4.

\begin{tabular}{|c|c|c|c|}
\hline \multirow[t]{2}{*}{ Teeth } & \multicolumn{3}{|c|}{ Material } \\
\hline & Composite & Compomer & Total \\
\hline \multicolumn{4}{|c|}{ Upper jaw } \\
\hline 54 & 1 & 1 & 15 \\
\hline 55 & 3 & 1 & \\
\hline 64 & 2 & 3 & \\
\hline 65 & 2 & 2 & \\
\hline \multicolumn{4}{|c|}{ Lower jaw } \\
\hline 74 & 4 & 6 & 33 \\
\hline 75 & 3 & 4 & \\
\hline 84 & 4 & 3 & \\
\hline 85 & 6 & 3 & \\
\hline Total & 25 & 23 & 48 \\
\hline
\end{tabular}




\section{DISCUSSION}

The treatment options for deep tooth decay extending to the pulp and with a substantial loss in tooth structure are limited compared to traditional restorative treatments. Various studies indicate that children between the age of 4 and 12 years, and their parents prefer restorations with better cosmetic appearance. ${ }^{[7-10]}$

It is suggested that the success of tooth-colored filling materials in pedodontics is based on the degree of the polymerization of resin composites. In direct

\begin{tabular}{|c|c|c|}
\hline \multicolumn{3}{|c|}{ Compomer } \\
\hline Gender & Teeth number & Time (days) \\
\hline Boy & 74,84 & 268 \\
\hline Boy & 75 & 345 \\
\hline Girl & 75 & 357 \\
\hline Girl & 74 & 479 \\
\hline \multicolumn{3}{|c|}{ Composite } \\
\hline Sex & Teeth number & Days \\
\hline Boy & 75 & 394 \\
\hline
\end{tabular}

placements, light energy is absorbed by the upper layer, creating layers of unpolymerized monomers as the restoration deepens, which affects the quality of restoration negatively, and the monomers also cause undesired reactions in the pulp. ${ }^{[11-15]}$ Therefore, to overcome these problems, extraoral polymerization using secondary polymerization methods were proposed. The effects of secondary polymerization by light-curing on composite resins have been studied by various researchers. ${ }^{[16-22]}$ In the present study, secondary polymerization was carried out using a "Lumamat 100 " furnace which is above the glass recycling level. ${ }^{[18]}$

In the restoration of primary teeth, abrasion characteristics of restorative material are desired to be close to the abrasion characteristics of the primary teeth. The use of hybrid resin composites was recommended in a study evaluating the placement of block crowns prepared to restore primary molar teeth. ${ }^{[23]}$ Therefore, $\mathrm{Z} 250$ resin composite with a hybrid structure was preferred.

The clinical success of onlay resin composite with respect to resin compomer restorations was evaluated according to USPHS criteria.

\begin{tabular}{|c|c|c|c|c|c|c|c|c|c|c|c|c|c|c|}
\hline & \multicolumn{2}{|c|}{ Baseline } & \multicolumn{2}{|c|}{3 months } & \multicolumn{2}{|c|}{6 months } & \multicolumn{2}{|c|}{9 months } & \multicolumn{2}{|c|}{12 months } & \multicolumn{2}{|c|}{15 months } & \multicolumn{2}{|c|}{ Success rate $(\%)$} \\
\hline & $\mathbf{A}^{+}$ & B & A & B & A & B & A & B & A & B & A & B & A & B \\
\hline \multicolumn{15}{|c|}{ Anatomic form } \\
\hline $1^{*}$ & 23 & 25 & 23 & 25 & 23 & 25 & 21 & 25 & 19 & 25 & 18 & 24 & 100 & 100 \\
\hline 2 & - & - & - & - & - & - & - & - & - & - & - & - & & \\
\hline \multicolumn{15}{|c|}{ Marginal adaptation } \\
\hline 1 & 23 & 25 & 23 & 25 & 23 & 25 & 21 & 25 & 19 & 25 & 18 & 24 & 100 & 100 \\
\hline 2 & - & - & - & - & - & - & - & - & - & - & - & - & & \\
\hline \multicolumn{15}{|c|}{ Color match } \\
\hline 1 & 23 & 25 & 23 & 25 & 23 & 25 & 21 & 25 & 19 & 25 & 18 & 24 & 100 & 100 \\
\hline 2 & - & - & - & - & - & - & - & - & - & - & - & - & & \\
\hline \multicolumn{15}{|c|}{ Marginal discoloration } \\
\hline 1 & 23 & 25 & 23 & 25 & 23 & 25 & 21 & 25 & 19 & 25 & 18 & 23 & 100 & 95 \\
\hline 2 & - & - & - & - & - & - & - & - & - & - & - & 1 & & \\
\hline \multicolumn{15}{|c|}{ Secondary caries } \\
\hline 1 & 23 & 25 & 23 & 25 & 23 & 25 & 21 & 25 & 19 & 25 & 18 & 24 & 100 & 100 \\
\hline 2 & - & - & - & - & - & - & - & - & - & - & - & - & & \\
\hline \multicolumn{15}{|c|}{ Surface structure } \\
\hline 1 & 23 & 25 & 23 & 25 & 23 & 25 & 21 & 25 & 19 & 25 & 18 & 24 & 100 & 100 \\
\hline 2 & - & - & - & - & - & - & - & - & - & - & - & - & & \\
\hline \multicolumn{15}{|c|}{ Restoration retention } \\
\hline 1 & 23 & 25 & 23 & 25 & 23 & 25 & 21 & 25 & 19 & 25 & 18 & 24 & 78 & 96 \\
\hline 2 & - & - & - & - & - & - & 2 & - & 4 & - & 5 & 1 & & \\
\hline \multicolumn{15}{|c|}{ Radiographic success } \\
\hline 1 & 23 & 25 & 23 & 25 & 23 & 25 & 21 & 25 & 19 & 25 & 18 & 24 & 100 & 100 \\
\hline 2 & - & - & - & - & - & - & - & - & - & - & - & - & & \\
\hline
\end{tabular}


Gok Coban, et al.: Onlay restorations on primary teeth

\begin{tabular}{|c|c|c|c|c|c|c|}
\hline & \multicolumn{3}{|c|}{ Compomer resin } & \multicolumn{3}{|c|}{ Composite resin } \\
\hline & Average & SD & $\begin{array}{c}\text { Average } \\
\text { rank }\end{array}$ & Average & SD & $\begin{array}{c}\text { Average } \\
\text { rank }\end{array}$ \\
\hline \multicolumn{7}{|c|}{$\mathrm{OHI}-\mathrm{S}$} \\
\hline 1 & 1.687 & 0.3571 & $5.65^{\mathrm{a}}$ & 1.081 & 0.3614 & $5.48^{a}$ \\
\hline 2 & 1.313 & 0.2181 & $4.30^{\mathrm{a}, \mathrm{b}}$ & 0.989 & 0.4132 & $4.98^{a}$ \\
\hline 3 & 1.078 & 0.2662 & $2.74^{c}$ & 0.674 & 0.2754 & $3.27^{\mathrm{b}}$ \\
\hline 4 & 1.057 & 0.2174 & $2.72^{c}$ & 0.639 & 0.2375 & $3.00^{\mathrm{b}}$ \\
\hline 5 & 0.985 & 0.0490 & $2.54^{c}$ & 0.531 & 0.2199 & $2.14^{b}$ \\
\hline 6 & 1.072 & 0.2065 & $3.04^{b, c}$ & 0.531 & 0.2199 & $2.14^{b}$ \\
\hline
\end{tabular}

The same and common letters indicate test at statistically meaningless. OHI-S: Oral Hygiene Index-Simplified, SD: Standard deviation

The clinical success of onlay restorations was determined at the baseline and at 3-month periods. At the end of 15 months, the success rates in all criteria except longevity and marginal discoloration were $100 \%$ for both materials, and there was no difference between the materials. The longevity of restoration was $78 \%$ and $96 \%$, and marginal discoloration was 100\% and $95 \%$ for the compomer and the resin composite, respectively. Although marginal discoloration was observed only in a single resin composite restoration, the failure rate appears to be high due to the small number of patients.

The restorations in terms of anatomic form were successful. This finding is similar to those obtained in studies using the direct placement method. ${ }^{[24-29]}$

Compomer restorations achieved a higher success rate compared to resin composite restorations in terms of marginal discoloration. The findings of the study suggest that the indirect method proves successful in terms of marginal adaptation and color match. Material, dentist's technique, and experience were reported to cause a decline in clinical performance by adhesion. ${ }^{[30,31]}$ During the 15-month follow-up, in terms of the development of secondary decays, both compomer and resin composite materials achieved a $100 \%$ success rate. The use of the indirect method eliminated the requirement to use matrix band, provided convenience by reducing the total procedure time, and ensured almost perfect marginal adaptation.

It is reported that secondary caries is the first cause of the renewal of restoration, which is followed by fractures or total loss of restoration. ${ }^{[32]}$ Studies evaluating the clinical success of direct restoration of the posterior primary teeth indicated a success rate of $85.8 \%-100 \%$ for resin composites and $75 \%-100 \%$ for resin compomers in terms of the integrity of restoration. ${ }^{[9,24,25,33-39]}$

Of 48 restorations performed in this study, 6 (5 compomer, 1 composite) were considered unsuccessful in terms of retention. The fracture of restoration or secondary caries was not observed in any of the lost restorations. We observed that four compomer restorations were lost between 9 and 16 months. All lost restorations were from the lower jaw. The finding that restorations were often lost from the first molar teeth could be attributed to low restoration and enamel thickness. The radiographic evaluation did not point to a pulpal pathology.

OHI-S of children increased with respect to the baseline levels. It should also be noted that oral hygiene training repeated at each quarterly visit, along with the positive motivation caused by better cosmetic appearance may have contributed to the improvement in oral hygiene. While an increase was observed in the depth of gingival sulcus, the values were within normal ranges and close to the values observed in the control group included in the previous study.

The evaluation of indirect onlay restorations performed in the current study did not reveal any significant difference between restorative materials. Using the indirect method, Dyract eXtra yielded a success rate of $78 \%-100 \%$, whereas Z250 yielded $96 \%-100 \%$, respectively. These findings are in conformity with previous studies. ${ }^{[9,26,30,33,36-41]}$

\section{CONCLUSION}

In this in vivo study, the rate of overall success and survival of restorations were high. The high survival rate of restorations in the current study is the result of almost perfect extraoral preparation of the forms, beveling and occlusal loading locations of restorations using the indirect placement technique, as well as the secondary polymerization applied to improve physical and cosmetic characteristics.

\section{Financial support and sponsorship}

Nil.

\section{Conflicts of interest}

There are no conflicts of interest.

\section{REFERENCES}

1. El-Mowafy O. Management of extensive carious lesions in permanent molars of a child with nonmetallic bonded restorations - A case report. 
J Can Dent Assoc 2000;66:302-7.

2. Hornbrook DS, Crispin BJ. Indirect and direct composite restorations. In: Crispin BJ, editor. Contemporary Esthetic Dentistry: Practice Fundamentals. Tokyo: Quintessence Publishing Company; 1994. p. 137-54.

3. Özgünaltay G, Görücü J, Tiritoğlu M. Glass ionomer cement fillings in the vicinity of the study of the decays generated by the in vitro method. Dental Journal of Dicle 1995;6:103-7.

4. Hickel R, Dasch W, Janda R, Tyas M, Anusavice K. New direct restorative materials. FDI commission project. Int Dent J 1998;48:3-16.

5. Shinkai K, Suzuki S, Leinfelder KF, Katoh Y. How heat treatment and thermal cycling affect wear of composite resin inlays. J Am Dent Assoc 1994;125:1467-72.

6. Frankl SN, Shiere FR, Fogels HR. Should the parent remain with the child in the dental operatory? J Dent Child 1962;29:150-63.

7. Özyöney G. Clinical and in vitro evaluation of ips empress ii onlay restorations on extensively damaged teeth. Istanbul: Marmara University Health Sciences institude, PhD thesis; 2008.

8. Fishman R, Guelmann M, Bimstein E. Children's selection of posterior restorative materials. J Clin Pediatr Dent 2006;31:1-4.

9. Atieh M. Stainless steel crown versus modified open-sandwich restorations for primary molars: A 2-year randomized clinical trial. Int J Paediatr Dent 2008;18:325-32.

10. Bell SJ, Morgan AG, Marshman Z, Rodd HD. Child and parental acceptance of preformed metal crowns. Eur Arch Paediatr Dent 2010;11:218-24.

11. Hume WR, Gerzina TM. Bioavailability of components of resin-based materials which are applied to teeth. Crit Rev Oral Biol Med 1996;7:172-9.

12. Geurtsen W, Lehmann F, Spahl W, Leyhausen G. Cytotoxicity of 35 dental resin composite monomers/additives in permanent 3T3 and three human primary fibroblast cultures. J Biomed Mater Res 1998;41:474-80.

13. Kırzıoğlu Z, Yılmaz Y, Bayındır Y. The evaluation of microleakage on beta-quartz inserts, prepolymerized resin composite balls, incremental and bulk insertion methods. The Journal of Dental Faculty of Ataturk University 1998;8:11-6.

14. Davidson CL, de Gee AJ. Light-curing units, polymerization, and clinical implications. J Adhes Dent 2000;2:167-73.

15. Guiraldo RD, Consani S, Lympius T, Schneider LF, Sinhoreti MA, Correr-Sobrinho L. Influence of the light curing unit and thickness of residual dentin on generation of heat during composite photoactivation. J Oral Sci 2008;50:137-42.

16. Wendt SL Jr. The effect of heat used as a secondary cure upon the physical properties of three composite resins. I. Diametral tensile strength, compressive strength, and marginal dimensional stability. Quintessence Int 1987;18:265-71.

17. Wendt SL Jr. The effect of heat used as secondary cure upon the physical properties of three composite resins. II. Wear, hardness, and color stability. Quintessence Int 1987;18:351-6.

18. Peutzfeldt A, Asmussen E. The effect of postcuring on quantity of remaining double bonds, mechanical properties, and in vitro wear of two resin composites. J Dent 2000;28:447-52.

19. Casselli DS, Worschech CC, Paulillo LA, Dias CT. Diametral tensile strength of composite resins submitted to different activation techniques. Braz Oral Res 2006;20:214-8.

20. Bertassoni LE, Marshall GW, de Souza EM, Rached RN. Effect of pre-and postpolymerization on flexural strength and elastic modulus of impregnated, fiber-reinforced denture base acrylic resins. J Prosthet Dent 2008;100:449-57.

21. Miyazaki CL, Medeiros IS, Santana IL, Matos Jdo R, Rodrigues Filho LE. Heat treatment of a direct composite resin: Influence on flexural strength. Braz Oral Res 2009;23:241-7.
22. Romieu O, Levallois B, Gal JY. Comparative study of flouride relase by two compomers with or without post-polymerization, in water and in artificial saliva (SAGF medium). Eur Cells Mater 2005;9:68-70.

23. Wada K, Miyashin M, Nango N, Takagi Y. Wear of resin composites and primary enamel and their applicability to full crown restoration of primary molars. Am J Dent 2011;24:67-73.

24. Papagiannoulis L, Kakaboura A, Pantaleon F, Kavvadia K. Clinical evaluation of a polyacid-modified resin composite (compomer) in class II restorations of primary teeth: A two-year follow-up study. Pediatr Dent 1999;21:231-4.

25. Welbury RR, Shaw AJ, Murray JJ, Gordon PH, McCabe JF. Clinical evaluation of paired compomer and glass ionomer restorations in primary molars: Final results after 42 months. Br Dent J 2000;189:93-7.

26. Pascon FM, Kantovitz KR, Caldo-Teixeira AS, Borges AF, Silva TN, Puppin-Rontani RM, et al. Clinical evaluation of composite and compomer restorations in primary teeth: $24-$ month results. J Dent 2006;34:381-8.

27. Memarpour M, Mesbahi M, Shafiei F. Three-and-a-half-year clinical evaluation of posterior composite resin in children. J Dent Child (Chic) 2010;77:92-8

28. Villalta P, Oliveira LB, Imparato JC, Rodrigues CR. Indirect composite onlay restorations in primary molars: A clinical report. J Clin Pediatr Dent 2006;31:17-20.

29. Cehreli ZC, Cetinguc A, Cengiz SB, Altay AN. Clinical performance of pulpotomized primary molars restored with resin-based materials 24-month results. Am J Dent 2006;19:262-6.

30. Andersson-Wenckert IE, Folkesson UH, van Dijken JW. Durability of a polyacid-modified composite resin (compomer) in primary molars. A multicenter study. Acta Odontol Scand 1997;55:255-60.

31. Gündoğdu N. Clinical success of restorations apllied with defferent techniques to the deciduous teeth and the in vivo study on microleakages. Erzurum, Turkey: Ataturk University, Institute of Medical Sciences, PhD thesis; 1998

32. Mjör IA, Dahl JE, Moorhead JE. Placement and replacement of restorations in primary teeth. Acta Odontol Scand 2002;60:25-8.

33. Soncini JA, Maserejian NN, Trachtenberg F, Tavares M, Hayes C. The longevity of amalgam versus compomer/composite restorations in posterior primary and permanent teeth: Findings from the New England children's amalgam trial. J Am Dent Assoc 2007;138:763-72.

34. Motokawa W, Braham RL, Teshima B. Clinical evaluation of light-cured composite resin inlays in primary molars. Am J Dent 1990;3:115-8.

35. Kilpatrick NM. Durability of restorations in primary molars. J Dent 1993;21:67-73.

36. Olmez A, Cula S, Ulusu T. Clinical evaluation and marginal leakage of Amalgambond Plus: Three-year results. Quintessence Int 1997;28:651-6.

37. Hse KM, Wei SH. Clinical evaluation of compomer in primary teeth: 1-year results. J Am Dent Assoc 1997;128:1088-96.

38. Attin T, Opatowski A, Meyer C, Zingg-Meyer B, Buchalla W, Mönting JS. Three-year follow up assessment of class II restorations in primary molars with a polyacid-modified composite resin and a hybrid composite. Am J Dent 2001;14:148-52.

39. Gross LC, Griffen AL, Casamassimo PS. Compomers as class II restorations in primary molars. Pediatr Dent 2001;23:24-7.

40. Qvist V, Poulsen A, Teglers PT, Mjör IA. The longevity of different restorations in primary teeth. Int J Paediatr Dent 2010;20:1-7.

41. Duggal MS, Toumba KJ, Sharma NK. Clinical performance of a compomer and amalgam for the interproximal restoration of primary molars: A 24-month evaluation. Br Dent J 2002;193:339-42. 